\title{
Effectiveness and safety of tofacitinib in rheumatoid arthritis: a cohort study
}

Marina Amaral de Ávila Machado', Cristiano Soares de Moura', Steve Ferreira Guerra', Jeffrey R. Curtis², Michal Abrahamowicz ${ }^{1,3}$ and Sasha Bernatsky ${ }^{1,3^{*}}$

\begin{abstract}
Background: Tofacitinib is the first oral Janus kinase inhibitor approved for the treatment of rheumatoid arthritis (RA). We compared the effectiveness and safety of tofacitinib, disease-modifying antirheumatic drugs (DMARDs), tumor necrosis factor inhibitors (TNFi), and non-TNF biologics in patients with RA previously treated with methotrexate.

Methods: We used MarketScan ${ }^{\oplus}$ databases (2011-2014) to study methotrexate-exposed patients with RA who were newly prescribed tofacitinib, DMARDs other than methotrexate, and biologics. The date of first prescription was defined as the cohort entry. The therapy was considered effective if all of the following criteria from a claims-based algorithm were achieved at the first year of follow-up: high adherence, no biologic or tofacitinib switch or addition, no DMARD switch or addition, no increase in dose or frequency of index drug, no more than one glucocorticoid joint injection, and no new/increased oral glucocorticoid dose. The safety outcome was serious infections requiring hospitalization. Non-TNF biologics comprised the reference group.

Results: We included 21,832 patients with RA, including 0.8\% treated with tofacitinib, 24.7\% treated with other DMARDs, $61.2 \%$ who had started therapy with TNFi, and 13.3\% treated with non-TNF biologics. The rates of therapy effectiveness were $15.4 \%$ for tofacitinib, $11.1 \%$ for DMARDs, $18.6 \%$ for TNFi, and 19.8\% for non-TNF biologics. In adjusted analyses, tofacitinib and non-TNF biologics appeared to have similar effectiveness rates, whereas DMARD initiators were less effective than non-TNF biologics. We could not clearly establish if tofacitinib was associated with a higher rate of serious infections.
\end{abstract}

Conclusions: In patients with RA previously treated with methotrexate, our comparisons of tofacitinib with non-TNF biologics, though not definitive, did not demonstrate differences with respect to hospitalized infections or effectiveness.

Keywords: Rheumatoid arthritis, Tofacitinib, Disease-modifying antirheumatic drug, Biologic therapy, Comparative effectiveness research

\section{Background}

New strategies have been developed to treat rheumatoid arthritis (RA) by inhibiting Janus kinase (JAK) pathways. The first JAK inhibitor approved for the treatment of RA in the United States (November 2012) was tofacitinib. This drug is an oral small molecule and recommended by both the American College of Rheumatology (ACR) and

\footnotetext{
* Correspondence: sasha.bernatsky@mcgill.ca

1 Division of Clinical Epidemiology, Research Institute of McGill University Health Centre, 5252 de Maisonneuve West, Montreal, QC, Canada

${ }^{3}$ Department of Epidemiology, Biostatistics and Occupational Health,

Research Institute of McGill University Health Centre, 5252 de Maisonneuve

West, Montreal, QC, Canada

Full list of author information is available at the end of the article
}

the European League Against Rheumatism (EULAR) as an alternative to biologic drugs when a patient remains with moderate or high disease activity after a first-line diseasemodifying antirheumatic drug (DMARD), usually methotrexate, in patients with established RA $[1,2]$.

Indirect comparisons have suggested that patients with RA in whom DMARD treatment fails experience similar efficacy in response to tumor necrosis factor inhibitors (TNFi), abatacept, tocilizumab, or tofacitinib (monotherapy or in combination with methotrexate). However, caution must be taken when interpreting that result because indirect comparisons are potentially biased [3]. Researchers studying a cohort derived from U.S. administrative 
databases (2012-2014) reported that patients using tofacitinib, etanercept, adalimumab, and abatacept had similar persistence and adherence at the end of the first year of therapy [4]. In terms of drug safety, it is well known that RA therapies can exacerbate the risk for herpes virus, and evidence from phase III and long-term extension of randomized controlled trials (RCTs) suggests that patients treated with tofacitinib have a higher incidence of herpes virus infection than those treated with placebo or adalimumab [5]. Another systematic review demonstrated that RCTs might not be sensitive enough to compare the risk of adverse events with tofacitinib [6], whereas researchers in one cohort study reported a higher risk for herpes virus infection with tofacitinib than with abatacept, TNFi, and other RA biologics [7]. Thus, the long-term safety of tofacitinib remains mostly uncertain.

More real-world evidence generated during routine clinical practice and obtained outside the context of RCTs is needed [8]. RCTs are typically planned to assess efficacy outcomes and are underpowered for detecting adverse events. Also, follow-up duration in RCTs is short, and long-term extension studies are potentially affected by healthy user bias. Evidence on new drug therapies is required throughout the entire product life cycle, therefore there has been increased interest in comparative effectiveness research on interventions to inform regulatory bodies for health care decision-making and to support optimization of practitioners' strategies for the management of RA [9].

To provide direct comparative evidence for tofacitinib's effectiveness and to expand the safety literature as well, we performed a study using real-world population data of tofacitinib, DMARDs, TNFi, and non-TNF biologics for patients with RA. ACR and EULAR recommend tofacitinib after a trial of methotrexate [1, 2]; thus, we studied patients with RA who had been or were exposed to methotrexate.

\section{Methods}

In this retrospective cohort study, we used data from the MarketScan ${ }^{\circ}$ Commercial Claims and Encounters database and the MarketScan Medicare Supplemental and Coordination of Benefits database (Truven Health Analytics, Ann Arbor, MI, USA) for the period between January 1, 2010, and December 31, 2014. These databases contain claims data for millions of privately insured individuals and their dependents, with many different health plans from large employers, indemnity plans, and health maintenance organizations as well as Medicare-covered patients. These databases include inpatient and outpatient visits, emergency room visits, and outpatient prescription drug information and have been widely used for diverse studies, including RA [10, 11].
We studied adult individuals with RA (at least 18 years old) who were previously treated with methotrexate (oral or subcutaneous) and newly dispensed other DMARDs, biologics, and tofacitinib between January 1, 2011, and December 30, 2014 (see below for complete list of drugs). Patients could be currently using methotrexate. The date of the first medication claim, either an outpatient prescription or a procedure claim (in-office drug administration), was defined as the cohort entry. We selected individuals with no use of these medications any time before cohort entry (minimum 12 months), although previous use of DMARDs was allowed for individuals in the biologic and tofacitinib groups. Patients with RA were identified as individuals with at least one inpatient or two outpatient claims (30 to 365 days apart) with an International Classification of Diseases, Ninth Revision, Clinical Modification (ICD-9-CM), code for RA (714.0x or 714.3x). Patients were excluded if they had another diagnosis before cohort entry for which relevant biologics are also approved: ankylosing spondylitis (ICD-9-CM code 720.0x), chronic lymphocytic leukemia (204.1 x), Crohn's disease (555.xx), juvenile idiopathic arthritis (714.3x), non-Hodgkin's lymphoma (200.xx, 202.xx), plaque psoriasis $(696.1 \mathrm{x})$, psoriatic arthritis (696.0x), or ulcerative colitis (556.xx) [12-14]. We also restricted our analysis to individuals with 12 continuous months of medical and pharmacy coverage prior to cohort entry and for the duration of follow-up.

\section{Effectiveness analysis}

Patients were classified in mutually exclusive groups according to the medication classes dispensed/administered at the cohort entry: (1) DMARDs (sulfasalazine, leflunomide, hydroxychloroquine, and chloroquine), (2) TNFi (adalimumab, etanercept, infliximab, certolizumab, and golimumab) with or without DMARDs, (3) nonTNF biologics (abatacept, rituximab, and tocilizumab) with or without DMARDs, and (4) tofacitinib with or without DMARDs. For this analysis, each patient contributed one therapy episode in one group.

A given therapy was considered effective if the six criteria of a validated claims-based algorithm [14, 15] were achieved throughout 1 year after cohort entry. This algorithm was validated with a gold standard (Disease Activity Score in 28 joints) and presented high sensitivity (72\%), specificity (91\%), positive predictive value (76\%), and negative predictive value (90\%) [15]. For this analysis, we considered only patients with at least 1 year of follow-up. The algorithm criteria relate to changes in the initial therapy: (1) high adherence, (2) no biologic or tofacitinib switch or addition, (3) no DMARD switch or addition, (4) no increase in dose or frequency of index drug, (5) no more than one glucocorticoid joint injection, and (6) no new/increased oral glucocorticoid dose. The details of all criteria are presented in Table 1. Adherence 
Table 1 Claims-based algorithm for accessing effectiveness after one year of follow-up in patients with rheumatoid arthritis

\begin{tabular}{ll}
\hline Criteria & Description of criteria \\
\hline Criterion 1 & Adherence to therapy was defined \\
High adherence & as follows: \\
- For medications with pharmacy \\
Claims only: MPR $\geq 80 \%^{\mathrm{a}}$ \\
- For medications with procedure \\
claims only: \\
Etanercept: $\geq 48$ procedures \\
Adalimumab: $\geq 22$ procedures \\
Certolizumab: $\geq 22$ procedures \\
Golimumab: $\geq 11$ procedures \\
Infliximab: $\geq 8$ procedures \\
Rituximab: $\geq 4$ procedures \\
Abatacept: $\geq 11$ procedures \\
Tocilizumab: $\geq 11$ procedures
\end{tabular}
between months 4 and 12 of
Criterion 2

No prescription or procedure of

a new biologic or tofacitinib

during follow-up

Criterion 3

No DMARD switch or

addition

Criterion 4

No increase in dose or

frequency of index drug

Criterion 5

No more than one procedure for glucocorticoid joint injection follow-up

Criterion 6

No new/increased oral

glucocorticoid dose

No prescription or procedure of a new biologic or tofacitinib during follow-up

No prescription of a new DMARD between months 4 and 12 of follow-up

No increase in dose or frequency of index drug

- For medications with pharmacy claims only: $\geq 10 \%$ of the daily dose at any time during follow-up compared with the daily dose at cohort entry

- For medications with procedure claims only:

Adalimumab: $>25$ procedures Certolizumab: $>25$ procedures Golimumab: $>12$ procedures Infliximab: $>9$ procedures Rituximab: $>5$ procedures Abatacept: $>13$ procedures Tocilizumab: $>12$ procedures Etanercept: $>55$ procedures

No more than one procedure for glucocorticoid joint injection between months 4 and 12 of follow-up

No increase in dose of oral glucocorticoid

- For patients who received no prescriptions for oral glucocorticoids 6 months prior to cohort entry: $>30$ days of cumulative oral glucocorticoid between months 4 and 12 of follow-up

- For patients who received prescriptions for oral glucocorticoids 6 months prior to cohort entry: cumulative dose between months 7 and 12 of follow-up $\geq 120 \%$ cumulative dose 6 months prior to cohort entry

MPR Medication possession ratio, DMARD Disease-modifying antirheumatic drug Adapted from Curtis et al., 2011 [15]

a A patient was considered highly adherent if the total days' supply of drug divided by the total days of follow-up was $\geq 80 \%$ to prescribed medication was evaluated using the medication possession ratio (MPR), calculated as the total days' supply of drug divided by the total follow-up days. Patients with MPRs $\geq 80 \%$ were considered highly adherent (i.e., meeting criterion 1 ).

For procedure claims, we used the recommended treatment interval in the U.S. prescribing information to calculate adherence (criterion 1) and increase in biologic dose or frequency (criterion 4) [16-23]. To take into account the differences between prescription and procedure claims regarding the measures of both criteria 1 and 4 (as described above), we excluded patients with a mix of pharmacy and procedure claims for the same index biologic during the follow-up.

In each exposure group, we estimated the separate proportion and the $95 \%$ CIs of patients who met individual criteria, as well as the overall proportion of patients for whom the therapy was effective (according to the claims-based algorithm). We estimated adjusted risk ratios with 95\% CIs using Poisson regression with robust variance to quantify the relationships between the initiation of treatment with drugs in each exposure group and the effectiveness of the therapy, with non-TNF biologics with or without DMARDs as the reference category, given our particular interest in assessing secondline and subsequent therapies in RA. The models were adjusted for sex, age at entry, and year of cohort entry, as well as for potential confounders measured during 1 year prior to cohort entry: Charlson comorbidity index; hospitalized infection; binary indicators of use of selective cyclooxygenase- 2 inhibitors and nonsteroidal anti-inflammatory drugs; oral glucocorticoid use categorized as no use, use of $\leq 7.5 \mathrm{mg} /$ day of prednisone equivalent dose, or ever use of $>7.5 \mathrm{mg} /$ day of prednisone equivalent dose (assessed for each filled prescription); and four indicators of health service use, assessed by the number of (1) emergency department visits, (2) physician visits, (3) rheumatology visits, and (4) hospitalizations.

We performed two sensitivity analyses in which we tested the modified claims-based algorithm for assessing therapy effectiveness while eliminating one of the criteria. First, we excluded criterion 1 (high adherence) to avoid bias estimating adherence of drugs with different administration routes using health claims. Second, we excluded criterion 4 (no increase in dose or frequency of index drug), because patients starting therapy with tofacitinib and some biologics usually do not change the initial dose and/or the frequency.

\section{Safety analysis}

For the safety analysis, current drug exposure was modeled as a time-dependent variable. Accordingly, each 
subject's follow-up time was divided into consecutive time intervals with a new interval starting whenever the patient changed, interrupted, and/or started treatment with one of the drug groups of interest. Switching to another drug within the same exposure group was not considered a change of drug exposure. Patients were considered exposed during the days supplied for the prescribed medication or, in the case of an outpatient procedure, the number of days in the recommended treatment interval. We applied a maximum grace period of 90 days, implying that subjects were assumed to remain exposed for the most recently presented drug until 90 days after the end of the prescription or the start of a new drug, whichever came earlier. Within each interval, a patient was classified into one of the same exposure categories as above, plus a no-use category, based on his/her current medication exposure: (1) DMARDs, (2) TNFi with or without DMARDs, (3) non-TNF biologics with or without DMARDs, (4) tofacitinib with or without DMARDs, or (5) nonuse (if not currently in use of any of the drugs in these categories). The outcome was defined as the occurrence of serious infection requiring hospitalization identified from the primary diagnosis recorded in the hospitalization discharge records (ICD9-CM codes 001-139 or 480-486).

We estimated the rate of serious infections per 100 patient-years for each exposure group. We also estimated the adjusted HRs with 95\% CIs, using multivariable timedependent Cox proportional hazards regression to assess the risk of serious infections associated with the current use of drugs in different categories, represented by timedependent binary indicators (dummy variables). The nonTNF biologics with or without DMARDs group was the reference category. Adjustments were made for the same covariates described for the effectiveness analysis and additionally for four time-dependent variables indicating current use of methotrexate, current use of glucocorticoid (no use, $\leq 7.5 \mathrm{mg} /$ day, and $>7.5 \mathrm{mg} /$ day), previous use of biologics, and previous use of other DMARDs.

Patients were followed from cohort entry until the earliest date of either (1) the event (i.e., the first occurrence of a serious infection) or (2) censoring at the time of loss of medical or pharmacy coverage, inpatient death, or the end of the study (December 31, 2014). Thus, we considered only one event per patient. In the primary analyses, we allowed patients to continue in the analyses after a drug change placed them in a different exposure category, but in a sensitivity analysis we censored them after they stopped/switched their initial therapy.

We restricted this analysis to only patients covered by Medicare in a sensitivity analysis. The rationale was that patients from commercial health plans enter and leave the cohort according to their drug insurance plan, which can change over time as their employment changes, whereas the Medicare coverage was expected to be more stable. Thus, for commercially insured people, the data we held is only a sampling of their entire health history, and missing information for the remaining periods could have affected the accuracy of the analyses. The Medicare patients, on the other hand, remained in the cohort for the entire follow-up period.

In an additional sensitivity analysis of safety, we repeated our work in a new cohort of patients with RA requiring them to be exposed to biologics and then to have initiated a new biologic agent or tofacitinib. All analyses were conducted using SAS version 9.4 software (SAS Institute, Cary, NC, USA).

\section{Results}

A total of 21,832 patients with RA previously exposed to methotrexate met the inclusion criteria. The therapy at cohort entry included TNFi with or without DMARDs (61.2\%), DMARDs alone (24.7\%), non-TNF biologics with or without DMARDs (13.3\%), and tofacitinib with or without DMARDs (0.8\%). Baseline characteristics were similar across groups (Table 2).

\section{Effectiveness}

Overall, therapy effectiveness was rather low, below $20 \%$ for each exposure group (first row of Table 3), with the lowest rates being in the DMARDs-alone group (11\%). Patients using either TNFi or non-TNF biologics reached better effectiveness rates, followed by tofacitinib. Among the six criteria, high adherence had the lowest rates in all groups and was especially low for DMARDs alone and tofacitinib. For criterion 2 (no biologic or tofacitinib switch or addition), the highest rate observed was among tofacitinib users. For criterion 3 (no DMARD switch or addition), DMARDs had the lowest rate. All patients using tofacitinib met criterion 4 (no dose escalation). Joint injections (criterion 5) occurred less often among patients using DMARDs, and oral glucocorticoid dose increases (criterion 6) were least likely to happen in the TNFi group (Table 3).

In the multivariable analyses, DMARDs were significantly less likely than non-TNF biologics to be classified as effective (Table 4). For TNFi and the tofacitinib groups, the $95 \%$ CIs around the point estimates were fairly wide and precluded definitive conclusions.

The algorithm without criterion 1 (high adherence) showed that tofacitinib was more likely than non-TNF biologics to reach effectiveness (Additional file 1). When we excluded criterion 4 (no increase in dose or frequency of index drug), most of the multivariate results were similar to the primary analysis, but in addition TNFi were less effective than non-TNF biologics (Additional file 1). 
Table 2 Baseline characteristics of patients with rheumatoid arthritis included in the study

\begin{tabular}{|c|c|c|c|c|c|}
\hline Variable & $\begin{array}{l}\text { All patients } \\
(n=21,832)\end{array}$ & $\begin{array}{l}\text { DMARDs } \\
(n=5399)\end{array}$ & $\begin{array}{l}\text { TNFi } \pm \text { DMARDs } \\
(n=13,367)\end{array}$ & $\begin{array}{l}\text { Non-TNF biologics } \pm \\
\text { DMARDs }(n=2902)\end{array}$ & $\begin{array}{l}\text { Tofacitinib } \pm \text { DMARDs } \\
(n=164)\end{array}$ \\
\hline Female sex, \% & 77.0 & 76.8 & 76.1 & 81.4 & 78.7 \\
\hline Age, years, median (IQR) & $56(48-63)$ & $57(49-63)$ & $56(48-63)$ & $58(50-65)$ & $58(50-64)$ \\
\hline \multicolumn{6}{|l|}{ Year of cohort entry, \% } \\
\hline 2011 & 48.5 & 25.9 & 52.3 & 70.5 & 0 \\
\hline 2012 & 21.6 & 27.2 & 20.5 & 14.1 & 0.6 \\
\hline 2013 & 14.7 & 21.9 & 13.1 & 8.7 & 43.9 \\
\hline 2014 & 15.2 & 25.0 & 14.1 & 6.7 & 55.5 \\
\hline Urban residency, \% & 82.6 & 81.1 & 83.2 & 82.8 & 89.4 \\
\hline \multicolumn{6}{|l|}{ Oral glucocorticoid use, \% } \\
\hline No use & 32.3 & 29.2 & 33.4 & 33.0 & 31.0 \\
\hline$\leq 7.5 \mathrm{mg} /$ day of prednisone equivalent dose & 63.0 & 65.1 & 62.2 & 62.2 & 64.9 \\
\hline$>7.5 \mathrm{mg} /$ day of prednisone equivalent dose & 4.7 & 5.7 & 4.4 & 4.8 & 4.0 \\
\hline Nonsteroidal anti-inflammatory drug use, \% & 60.7 & 60.3 & 62.1 & 54.9 & 51.8 \\
\hline Selective COX-2 inhibitor use, \% & 12.8 & 10.9 & 12.9 & 16.0 & 13.4 \\
\hline Charlson comorbidity index, mean (SD) & $0.61(0.93)$ & $0.73(1.04)$ & $0.54(0.84)$ & $0.73(1.02)$ & $0.86(1.14)$ \\
\hline Infection-related hospitalization, \% & 1.6 & 1.9 & 1.3 & 2.6 & 1.8 \\
\hline Number of emergency department visits, mean (SD) & $0.44(1.20)$ & $0.48(1.39)$ & $0.42(1.14)$ & $0.44(1.05)$ & $0.43(0.83)$ \\
\hline Number of physician visits, mean (SD) & $17.99(13.26)$ & $17.32(14.07)$ & $17.37(12.24)$ & $22.21(15.24)$ & $16.70(14.24)$ \\
\hline Number of rheumatology visits, mean (SD) & $4.51(4.92)$ & $3.39(3.85)$ & $4.54(4.71)$ & $6.47(6.75)$ & $3.88(3.26)$ \\
\hline Number of hospitalizations, mean (SD) & $0.16(0.50)$ & $0.16(0.54)$ & $0.14(0.45)$ & $0.23(0.62)$ & $0.17(0.62)$ \\
\hline
\end{tabular}

Abbreviations: DMARD Disease-modifying antirheumatic drug, TNFi Tumor necrosis factor inhibitor, COX-2 Cyclooxygenase-2

Baseline variables were collected at cohort entry (sex, age, year of cohort entry, and place of residence) or 1 year prior to cohort entry (use of drugs, Charlson comorbidity index, hospitalized infection, and indicators of health service use)

\section{Safety}

Current use of tofacitinib was associated with a rate of serious infections of 3.67 per 100 patient-years, and the $95 \%$ CI for this estimate $(2.21 ; 5.75)$ overlapped with the rate of serious infections for the other drug groups (Table 5). In the multivariate analyses, the hazards of serious infection for DMARDs, TNFi, and tofacitinib were not significant different compared with non-TNF biologic. Current use of methotrexate, previous use of biologics, use of oral glucocorticoid in the year before cohort entry, and current use

Table 3 Proportion of patients who achieved therapy effectiveness and individual criteria at 1 year of follow-up $(n=16,305)$

\begin{tabular}{|c|c|c|c|c|c|c|c|c|}
\hline \multirow[t]{2}{*}{ Effectiveness criteria } & \multicolumn{2}{|c|}{ DMARDs } & \multicolumn{2}{|c|}{ TNFi \pm DMARDs } & \multicolumn{2}{|c|}{ Non-TNF biologics \pm DMARDs } & \multicolumn{2}{|c|}{ Tofacitinib \pm DMARDs } \\
\hline & Percent & $95 \% \mathrm{Cl}$ & Percent & $95 \% \mathrm{Cl}$ & Percent & $95 \% \mathrm{Cl}$ & Percent & $95 \% \mathrm{Cl}$ \\
\hline Effective therapy (satisfied all six criteria) & 11.1 & $10.1-12.1$ & 18.6 & $17.9-19.4$ & 19.8 & $18.2-21.4$ & 15.4 & $6.6-24.2$ \\
\hline $\begin{array}{l}\text { Criterion } 1 \\
\text { High adherence }\end{array}$ & 26.6 & $25.1-28.0$ & 44.0 & $43.0-44.9$ & 53.3 & $51.3-55.3$ & 27.7 & $16.8-38.6$ \\
\hline $\begin{array}{l}\text { Criterion } 2 \\
\text { No biologic or tofacitinib switch or addition }\end{array}$ & 72.7 & $71.2-74.1$ & 64.3 & $63.4-65.2$ & 82.1 & $80.5-83.6$ & 84.6 & $75.8-93.4$ \\
\hline $\begin{array}{l}\text { Criterion } 3 \\
\text { No DMARD switch or addition }\end{array}$ & 85.3 & $84.2-86.5$ & 96.1 & $95.8-96.5$ & 95.5 & $94.6-96.3$ & 98.5 & $95.5-100$ \\
\hline $\begin{array}{l}\text { Criterion } 4 \\
\text { No increase in dose or frequency of index drug }\end{array}$ & 92.0 & $91.1-92.9$ & 94.0 & $93.5-94.4$ & 88.9 & $87.6-90.1$ & $100.0^{\mathrm{a}}$ & - \\
\hline $\begin{array}{l}\text { Criterion } 5 \\
\text { No more than one glucocorticoid joint injection }\end{array}$ & 91.3 & $90.3-92.2$ & 88.8 & $88.2-89.4$ & 72.8 & $71.0-74.6$ & 87.7 & 79.7-95.7 \\
\hline $\begin{array}{l}\text { Criterion } 6 \\
\text { No new/increased oral glucocorticoid dose }\end{array}$ & 81.4 & $80.2-82.7$ & 83.3 & $82.6-84.1$ & 78.0 & $76.3-79.7$ & 76.9 & $66.7-87.2$ \\
\hline
\end{tabular}


Table 4 Adjusted risk ratio and 95\% Cl for medication effectiveness (algorithm result) $(n=16,305)$

\begin{tabular}{|c|c|c|}
\hline Parameter & $\begin{array}{l}\text { Adjusted risk } \\
\text { ratio }\end{array}$ & $95 \% \mathrm{Cl}$ \\
\hline \multicolumn{3}{|l|}{ Drug therapy } \\
\hline Non-TNF biologics \pm DMARDs & Reference & - \\
\hline DMARDs & 0.58 & $0.51-0.66$ \\
\hline TNFi \pm DMARDs & 0.94 & $0.86-1.03$ \\
\hline Tofacitinib \pm DMARDs & 0.75 & $0.42-1.34$ \\
\hline Sex (female) & 0.94 & $0.87-1.02$ \\
\hline Age & 1.01 & $1.00-1.01$ \\
\hline \multicolumn{3}{|l|}{ Year of cohort entry } \\
\hline 2011 & Reference & - \\
\hline 2012 & 0.87 & $0.8-0.95$ \\
\hline 2013 & 1.00 & $0.91-1.1$ \\
\hline \multicolumn{3}{|l|}{$\begin{array}{l}\text { Oral glucocorticoid use } 1 \text { year prior } \\
\text { to cohort entry }\end{array}$} \\
\hline No use & Reference & - \\
\hline $\begin{array}{l}\text { Use of } \leq 7.5 \mathrm{mg} / \text { day of prednisone } \\
\text { equivalent dose }\end{array}$ & 0.94 & $0.88-1.02$ \\
\hline $\begin{array}{l}\text { Use of }>7.5 \mathrm{mg} / \text { day of prednisone } \\
\text { equivalent dose }\end{array}$ & 1.07 & $0.90-1.26$ \\
\hline $\begin{array}{l}\text { Nonsteroidal anti-inflammatory drug } \\
\text { use } 1 \text { year prior to cohort entry }\end{array}$ & 0.94 & $0.88-1.01$ \\
\hline $\begin{array}{l}\text { Selective COX-2 inhibitors use } 1 \text { year } \\
\text { prior to cohort entry }\end{array}$ & 0.98 & $0.88-1.08$ \\
\hline $\begin{array}{l}\text { Charlson comorbidity index } 1 \text { year } \\
\text { prior to cohort entry }\end{array}$ & 0.91 & $0.86-0.95$ \\
\hline $\begin{array}{l}\text { Infection-related hospitalization } 1 \text { year } \\
\text { prior to cohort entry }\end{array}$ & 0.84 & $0.60-1.19$ \\
\hline $\begin{array}{l}\text { Number of emergency department } \\
\text { visits } 1 \text { year prior to cohort entry }\end{array}$ & 0.96 & $0.90-1.01$ \\
\hline $\begin{array}{l}\text { Number of physician visits } 1 \text { year } \\
\text { prior to cohort entry }\end{array}$ & 1.00 & $0.99-1.00$ \\
\hline $\begin{array}{l}\text { Number of rheumatology visits } 1 \text { year } \\
\text { prior to cohort entry }\end{array}$ & 1.00 & $1.00-1.01$ \\
\hline $\begin{array}{l}\text { Number of hospitalizations } 1 \text { year } \\
\text { prior to cohort entry }\end{array}$ & 0.97 & $0.89-1.06$ \\
\hline
\end{tabular}

Abbreviations: DMARD Disease-modifying antirheumatic drug, TNFi Tumor necrosis factor inhibitors, COX-2 Cyclooxygenase-2

Table 5 Crude incidence and 95\% Cls of serious infection $(n=21,832)$

\begin{tabular}{lclll}
\hline Drug therapy & Events & $\begin{array}{l}\text { Total person- } \\
\text { years }\end{array}$ & $\begin{array}{l}\text { Crude rate } \\
\text { (per 100 } \\
\text { patient-year) }\end{array}$ & $95 \% \mathrm{Cl}$ \\
\hline DMARDs & 104 & 5196.02 & 2.01 & $1.65-2.42$ \\
TNFi \pm DMARDs & 490 & $22,736.79$ & 2.16 & $1.98-2.36$ \\
$\begin{array}{l}\text { Non-TNF biologic } \\
\pm \text { DMARDs }\end{array}$ & 173 & 6936.41 & 2.49 & $2.14-2.88$ \\
$\begin{array}{l}\text { Tofacitinib } \pm \\
\text { DMARDs }\end{array}$ & 17 & 474.48 & 3.67 & $2.21-5.75$ \\
\hline
\end{tabular}

DMARDs Disease-modifying antirheumatic drugs, TNFi Tumor necrosis factor inhibitors of oral glucocorticoid were associated with significant increases in the current hazard of infections (Table 6).

Our findings were similar in the sensitivity analysis, where we censored patients after they discontinued or switched their initial therapy (Additional file 2). The analysis limited to Medicare data reduced the sample to 5200 patients. The incidence of serious infection was higher in the Medicare patients than in the primary analyses, across all exposure groups, but the HRs were generally similar to the primary analysis, despite the wide CIs (Additional file 3). Finally, in an additional sensitivity analysis in a new cohort of patients with RA previously exposed to a biologic agent, the results also indicated that tofacitinib was not significantly different from non-TNF biologics (Additional file 4).

\section{Discussion}

In this retrospective cohort study of patients previously treated with methotrexate, we evaluated the effectiveness and risk of serious infection of tofacitinib compared with DMARDs, TNFi, and non-TNF biologics. Effectiveness at 1 year of follow-up, estimated by a claims-based algorithm, was noted in 15\% of tofacitinib users, $11 \%$ of DMARD users, and around 19\% of TNFi and non-TNF biologic users. The adjusted analysis showed that patients using tofacitinib were as likely as non-TNF biologic users to show effectiveness. The algorithm measures effectiveness on the basis of changes of the initial therapy that can capture both lack of or low effectiveness as well as drug intolerance and side effects. Therefore, it may be expected that our results show lower "success" rates than RCTs. In addition of course, our "real-world" data reflect a different population from the relatively narrow and homogeneous range of subjects enrolled in RCTs, which also will result in different "success" rates as compared with RCTs.

Adherence was an important component in our effectiveness algorithms: less than half of patients in the TNFi and non-TNF biologic groups and only one-third in the tofacitinib and DMARD groups continued their initial therapy. This criterion does not distinguish between actual noncompliance with the treatment and intolerance or adverse events. Switching/addition was another important factor contributing to overall algorithm failure, particularly in the TNFi group. Note that patients using tofacitinib did not increase their initial dose, given that there is only one Food and Drug Administrationapproved dose. The adjusted comparisons of the final algorithm result suggested greater effectiveness for TNFi or non-TNF biologics than for DMARDs, and we were unable to establish differences for tofacitinib and DMARDs. In effect, tofacitinib appeared as effective as biologics on the basis of most criteria. Researchers in another cohort study using pharmacy claims reported a 
Table 6 Adjusted HRs and 95\% Cls for time to serious infection $(n=21,832)$

\begin{tabular}{|c|c|c|}
\hline Parameter & Adjusted HR & $95 \% \mathrm{Cl}$ \\
\hline \multicolumn{3}{|l|}{ Drug therapy } \\
\hline Non-TNF biologic \pm DMARDs & Reference & - \\
\hline DMARDs & 0.80 & $0.62-1.03$ \\
\hline TNFi \pm DMARDs & 1.14 & $0.95-1.37$ \\
\hline Tofacitinib \pm DMARDs & 1.54 & $0.93-2.56$ \\
\hline Current use of methotrexate ${ }^{a}$ & 1.19 & $1.04-1.37$ \\
\hline Previous use of biologics ${ }^{a}$ & 1.32 & $1.12-1.57$ \\
\hline Previous use of other DMARDs ${ }^{a}$ & 1.04 & $0.86-1.27$ \\
\hline Sex (female) & 1.02 & $0.87-1.18$ \\
\hline Age & 1.04 & $1.03-1.04$ \\
\hline \multicolumn{3}{|l|}{ Year of cohort entry } \\
\hline 2011 & Reference & - \\
\hline 2012 & 1.10 & $0.92-1.31$ \\
\hline 2013 & 0.85 & $0.66-1.08$ \\
\hline 2014 & 0.97 & $0.70-1.35$ \\
\hline \multicolumn{3}{|l|}{$\begin{array}{l}\text { Oral glucocorticoid use one year prior } \\
\text { to cohort entry }\end{array}$} \\
\hline No use & Reference & - \\
\hline $\begin{array}{l}\text { Use of } \leq 7.5 \mathrm{mg} / \text { day of prednisone } \\
\text { equivalent dose }\end{array}$ & 1.23 & $1.05-1.44$ \\
\hline $\begin{array}{l}\text { Use of }>7.5 \mathrm{mg} / \text { day of prednisone } \\
\text { equivalent dose }\end{array}$ & 1.36 & $1.00-1.84$ \\
\hline \multicolumn{3}{|l|}{ Current use of oral glucocorticoid ${ }^{a}$} \\
\hline No use & Reference & - \\
\hline $\begin{array}{l}\text { Use of } \leq 7.5 \mathrm{mg} / \text { day of prednisone } \\
\text { equivalent dose }\end{array}$ & 1.90 & $1.64-2.20$ \\
\hline $\begin{array}{l}\text { Use of }>7.5 \mathrm{mg} / \text { day of prednisone } \\
\text { equivalent dose }\end{array}$ & 2.83 & $1.37-5.83$ \\
\hline $\begin{array}{l}\text { Nonsteroidal anti-inflammatory drugs } \\
\text { use } 1 \text { year prior to cohort entry }\end{array}$ & 0.93 & $0.81-1.06$ \\
\hline $\begin{array}{l}\text { Selective COX-2 inhibitors use } 1 \text { year } \\
\text { prior to cohort entry }\end{array}$ & 1.13 & $0.95-1.35$ \\
\hline $\begin{array}{l}\text { Charlson comorbidity index } 1 \text { year } \\
\text { prior to cohort entry }\end{array}$ & 1.72 & $1.49-1.99$ \\
\hline $\begin{array}{l}\text { Infection related hospitalization } 1 \text { year } \\
\text { prior to cohort entry }\end{array}$ & 2.19 & $1.68-2.86$ \\
\hline $\begin{array}{l}\text { Number of emergency department } \\
\text { visits } 1 \text { year prior to cohort entry }\end{array}$ & 1.04 & $1.01-1.06$ \\
\hline $\begin{array}{l}\text { Number of physician visits } 1 \text { year prior } \\
\text { to cohort entry }\end{array}$ & 1.01 & $1.00-1.01$ \\
\hline $\begin{array}{l}\text { Number of rheumatology visits } 1 \text { year } \\
\text { prior to cohort entry }\end{array}$ & 1.00 & $0.99-1.02$ \\
\hline $\begin{array}{l}\text { Number of hospitalizations } 1 \text { year } \\
\text { prior to cohort entry }\end{array}$ & 1.33 & $1.24-1.43$ \\
\hline
\end{tabular}

DMARDs Disease-modifying antirheumatic drug, TNFi Tumor necrosis factor inhibitors

${ }^{\text {aTime-varying covariates }}$ similar proportion of persistence and adherence (measured by proportion of days covered) at the first year of therapy among patients using tofacitinib, etanercept, adalimumab, and abatacept. A greater proportion of patients using etanercept and adalimumab switched to tofacitinib or another biologic. Finally, dose increase happened in $5 \%$ of patients using tofacitinib [4].

Our study shows that the unadjusted incidence of hospitalizations for infection was 3.6 per 100 patientyears for tofacitinib, compared with 2.2 and 2.5 per 100 patient-years in individuals using TNFi and non-TNF biologics, respectively. Higher rates were observed in each of these groups in the cohort containing only patients covered by Medicare (aged $>65$ years). Recent cohort studies showed different point estimates for DMARDs and biologic agents [24-26], which may be explained by the difference in the definition of serious infections, by differences in patients' profiles regarding other risk factors for infections, or perhaps by chance alone. Our adjusted comparisons did not demonstrate that tofacitinib users had an increased risk of serious (hospitalized) infections compared with those treated with non-TNF biologics. One recent study using Medicare and MarketScan databases showed that patients using tofacitinib had a higher risk for herpes virus infection than those using biologic drugs [7]. Although the aim of our study was not to directly compare infection risk of tofacitinib patients with that of those treated with anti-TNF drugs only, we performed this comparison and did not find a significant difference. Factors that were associated with higher risk of infection in our study were current use of methotrexate, use of oral glucocorticoid before cohort entry, and previous use of biologics.

In our sample, after a first treatment with methotrexate, tofacitinib was not commonly prescribed. Although the ACR and EULAR guidelines recommend the use of tofacitinib after failure of therapy with DMARDs in patients with established RA, others argue that the JAK inhibitors (owing to the uncertainty about long-term safety and cost-effectiveness) should be used only after insufficient response to initial biologic treatment [27]. The dearth of evidence from observational studies to date was in part the motivation for our work in this analysis to inform the comparative effectiveness and safety of tofacitinib. Our additional analysis of tofacitinib after failure of a first biologic therapy for patients with RA showed similar safety in terms of serious (hospitalized) infection.

Our study has potential limitations. First, we obtained a small sample of tofacitinib users, which was expected for a novel therapy. The patients were not clinically confirmed, but we did use a validated RA definition; our patients were all previously exposed to the cornerstone RA therapy (methotrexate); and we excluded patients with other 
indications for various RA drug exposures (e.g., cancer, other rheumatic diseases). Still, although MarketScan databases collect data on a large population, it lacks data on important clinical variables and reasons for changing the initial therapy. As a result, we indirectly measured therapy effectiveness using an algorithm based on registers of drug prescriptions or drug administration. This algorithm is composed of criteria related to actionable interventions used by physicians. Although the algorithm has previously been validated for anti-TNF and DMARD therapy in RA, it seemed reasonable to apply the same set of criteria to measure the response to non-TNF biologics and tofacitinib as we did in our study. In addition, herpes zoster (which usually does not require hospitalization) is potentially an important infectious outcome but not one we focused on in this analysis.

All observational studies are at risk of "channeling"; that is, persons are not allocated drugs randomly, and the characteristics of certain people who tend to receive certain drugs may become confounders (e.g., RA disease duration and prior biologic use, which have been shown to be confounders of infection risk [28]) if those are also associated with the outcome of interest. So, for example, it may be that people assigned to tofacitinib were more or less likely (because of their past response to drugs in terms of effectiveness or infection) to have the outcome of interest. We aimed to overcome this potential issue by studying only those patients with RA with previous methotrexate exposure, and we also controlled for proxies of disease severity (e.g., past drugs and rheumatology visits).

We note that in the dataset that we used, patients' follow-up could have happened because of a loss or change in their health insurance. Medicare completely captures patients' claims, and the analysis restricted to those patients showed similar risk for infections, despite the lower precision.

As a final point that should be taken into account when interpreting and comparing our results, in our analyses, patients using biologics or tofacitinib could also be taking one or more DMARDs, including MTX. However, most of these combinations would be with drugs such as hydroxychloroquine, which itself tends not to increase infection risk.

\section{Conclusions}

In summary, in this report of a large population-based cohort study, we present novel data on real-world use of tofacitinib in patients with RA previously treated with methotrexate. Our study estimated similar (relatively low) effectiveness rates at 1 year of follow-up for patients starting tofacitinib after therapy with methotrexate, as opposed to initiators of non-TNF biologics. Our comparisons of tofacitinib versus non-TNF biologics, though not definitive, did not clearly demonstrate differences with respect to hospitalized infections.

\section{Additional files}

Additional file 1: Proportion and adjusted risk ratio of patients who achieved therapy effectiveness based on the modified algorithm ( $n=16,305)$. (DOCX $14 \mathrm{~kb}$ )

Additional file 2: Adjusted HR for time to serious infection in patients censored after they stopped/switched their initial therapy $(n=21,832)$. (DOCX $14 \mathrm{~kb}$ )

Additional file 3: Adjusted HR for time to serious infection in patients covered by Medicare $(n=5200)$. (DOCX $13 \mathrm{~kb}$ )

Additional file 4: Crude incidence of serious infection in patients with RA previously exposed to a biologic agent $(n=14,875)$. Adjusted HR for time to serious infection in patients with RA previously exposed to a biologic agent $(n=14,875)$. (DOCX $15 \mathrm{~kb})$

\section{Abbreviations}

ACR: American College of Rheumatology; COX-2: Cyclooxygenase-2; DMARD: Disease-modifying antirheumatic drug; EULAR: European League Against Rheumatism; ICD-9-CM: International Classification of Diseases, Ninth Revision, Clinical Modification; JAK: Janus kinase; MPR: Medication possession ratio; RA: Rheumatoid arthritis; RCT: Randomized controlled trial; TNFi: Tumor necrosis factor inhibitor(s)

\section{Acknowledgements}

Hassan Behlouli provided analytical support.

\section{Funding}

This work was funded by the Canadian Institutes of Health Research.

\section{Availability of data and materials}

The data that support the findings of this study are available from Truven Health MarketScan ${ }^{\oplus}$, but restrictions apply to the availability of these data, which were used under license for the present study and so are not publicly available. Data are, however, available from the authors upon reasonable request and with permission of Truven Health MarketScan ${ }^{\circledast}$.

\section{Authors' contributions}

MAAM contributed to the design, data analyses, data interpretation, and manuscript preparation. CSM contributed to the design, data analyses, data interpretation, and manuscript preparation. SFG contributed to data analyses and manuscript preparation. JRC contributed to the design, data interpretation, and manuscript preparation. MA contributed to acquisition of data, data analyses, data interpretation, and manuscript preparation. SB contributed to acquisition of data, study concept and design, data interpretation, and manuscript preparation. All authors read and approved the final manuscript.

Ethics approval and consent to participate

The study was approved by the Research Ethics Office of the Faculty of Medicine, McGill University (IRB Study Number A04-M47-12B).

Consent for publication

Not applicable.

Competing interests

The authors declare that they have no competing interests.

\section{Publisher's Note}

Springer Nature remains neutral with regard to jurisdictional claims in published maps and institutional affiliations. 


\section{Author details}

'Division of Clinical Epidemiology, Research Institute of McGill University Health Centre, 5252 de Maisonneuve West, Montreal, QC, Canada. ${ }^{2}$ Division of Clinical Immunology and Rheumatology, University of Alabama at Birmingham, 619 19th Street South, Birmingham, AL SRC 076, USA. ${ }^{3}$ Department of Epidemiology, Biostatistics and Occupational Health, Research Institute of McGill University Health Centre, 5252 de Maisonneuve West, Montreal, QC, Canada.

Received: 13 September 2017 Accepted: 8 February 2018 Published online: 23 March 2018

\section{References}

1. Singh JA, Saag KG, Bridges SL Jr, Akl EA, Bannuru RR, Sullivan MC, et al. 2015 American College of Rheumatology Guideline for the Treatment of Rheumatoid Arthritis. Arthritis Rheumatol. 2016;68(1):1-26.

2. Smolen JS, Landewé R, Bijlsma J, Burmester G, Chatzidionysiou K, Dougados $M$, et al. EULAR recommendations for the management of rheumatoid arthritis with synthetic and biological disease-modifying antirheumatic drugs: 2016 update. Ann Rheum Dis. 2017;76(6):960-77.

3. Buckley F, Finckh A, Huizinga TW, Dejonckheere F, Jansen JP. Comparative efficacy of novel DMARDs as monotherapy and in combination with methotrexate in rheumatoid arthritis patients with inadequate response to conventional DMARDs: a network meta-analysis. J Manag Care Spec Pharm. 2015;21(5):409-23.

4. Harnett J, Gerber R, Gruben D, Koenig AS, Chen C. Evaluation of real-world experience with tofacitinib compared with adalimumab, etanercept, and abatacept in RA patients with 1 previous biologic DMARD: data from a U.S. administrative claims database. J Manag Care Spec Pharm. 2016;22(12): 1457-71.

5. Winthrop KL, Yamanaka H, Valdez H, Mortensen E, Chew R, Krishnaswami S, et al. Herpes zoster and tofacitinib therapy in patients with rheumatoid arthritis. Arthritis Rheumatol. 2014;66(10):2675-84.

6. Souto A, Maneiro JR, Salgado E, Carmona L, Gomez-Reino JJ. Risk of tuberculosis in patients with chronic immune-mediated inflammatory diseases treated with biologics and tofacitinib: a systematic review and meta-analysis of randomized controlled trials and long-term extension studies. Rheumatology (Oxford). 2014;53(10):1872-85.

7. Curtis JR, Xie F, Yun H, Bernatsky S, Winthrop KL. Real-world comparative risks of herpes virus infections in tofacitinib and biologic-treated patients with rheumatoid arthritis. Ann Rheum Dis. 2016;75(10):1843-7.

8. Berger ML, Sox H, Willke RJ, Brixner DL, Eichler HG, Goettsch W, et al. Good practices for real-world data studies of treatment and/or comparative effectiveness: recommendations from the joint ISPOR-ISPE Special Task Force on real-world evidence in health care decision making. Pharmacoepidemiol Drug Saf. 2017;26(9):1033-9.

9. Berger ML, Dreyer N, Anderson F, Towse A, Sedrakyan A, Normand SL. Prospective observational studies to assess comparative effectiveness: the ISPOR good research practices task force report. Value Health. 2012;15(2):217-30

10. Gu NY, Huang XY, Fox KM, Patel VD, Baumgartner SW, Chiou CF. Claims data analysis of dosing and cost of TNF antagonists. Am J Pharm Benefits. 2010;2:351-9.

11. Petri $H$, Maldonato $D$, Robinson NJ. Data-driven identification of comorbidities associated with rheumatoid arthritis in a large US health plan claims database. BMC Musculoskelet Disord. 2010;11:247.

12. Curtis JR, Schabert VF, Harrison DJ, Yeaw J, Korn JR, Quach C, et al. Estimating effectiveness and cost of biologics for rheumatoid arthritis: application of a validated algorithm to commercial insurance claims. Clin Ther. 2014;36(7):996-1004.

13. Sauer BC, Teng CC, He T, Leng J, Lu CC, Curtis JR, Cannon GW. Effectiveness and costs of biologics in veterans with rheumatoid arthritis. Am J Pharm Benefits. 2015;7(6):280-9.

14. Bonafede M, Johnson BH, Princic N, Shah N, Harrison DJ. Cost per patientyear in response using a claims-based algorithm for the 2 years following biologic initiation in patients with rheumatoid arthritis. J Med Econ. 2015; 18(5):376-89.

15. Curtis JR, Baddley JW, Yang S, Patkar N, Chen L, Delzell E, et al. Derivation and preliminary validation of an administrative claims-based algorithm for the effectiveness of medications for rheumatoid arthritis. Arthritis Res Ther 2011;13(5):R155.
16. Genentech I. Actemra (tocilizumab) prescribing information. South San Francisco, CA: Genentech, Inc.; 2017.

17. UCB, Inc. Cimzia (certolizumab pegol) prescribing information. Smyrna, GA: UCB, Inc.; 2013.

18. Corporation I. Enbrel (etanercept) prescribing information. Thousand Oaks, CA: Immunex Corporation; 2013.

19. Laboratories A. Humira (adalimumab) prescribing information. North Chicago, IL: Abbott Laboratories; 2014.

20. Bristol-Myers Squibb Company. Orencia (abatacept) prescribing information. Princeton, NJ: Bristol-Myers Squibb Company; 2014.

21. Centocor Ortho Biotech, Inc. Remicade (infliximab) prescribing information. Malvern, PA: Centocor Ortho Biotech, Inc.; 2013.

22. Biogen/Genentech USA, Inc. Rituxan (rituximab) prescribing information. South San Francisco, CA: Biogen/Genentech USA, Inc:; 2016.

23. Biotech J. Inc. Simponi (golimumab) prescribing information. Horsham, PA: Janssen Biotech, Inc.; 2014.

24. Dixon WG, Symmons DP, Lunt M, Watson KD, Hyrich KL, British Society for Rheumatology Biologics Register Control Centre Consortium, et al. Serious infection following anti-tumor necrosis factor alpha therapy in patients with rheumatoid arthritis: lessons from interpreting data from observational studies. Arthritis Rheum. 2007;56(9):2896-904.

25. Curtis JR, Yang S, Patkar NM, Chen L, Singh JA, Cannon GW, et al. Risk of hospitalized bacterial infections associated with biologic treatment among US veterans with rheumatoid arthritis. Arthritis Care Res (Hoboken). 2014; 66(7):990-7.

26. Kawashima H, Kagami SI, Kashiwakuma D, Takahashi K, Yokota M, Furuta S, et al. Long-term use of biologic agents does not increase the risk of serious infections in elderly patients with rheumatoid arthritis. Rheumatol Int. 2017; 37(3):369-76.

27. Kissin EY. The "dirty little secret" exposed in the 2013 EULAR recommendations for rheumatoid arthritis therapy. Clin Ther. 2014;36(7): $1114-6$.

28. Curtis JR, Xie F, Chen L, Baddley JW, Beukelman T, Saag KG, et al. The comparative risk of serious infections among rheumatoid arthritis patients starting or switching biological agents. Ann Rheum Dis. 2011;70(8):1401-6. 